\title{
Coronary artery surgery: indications and recent experience
}

\author{
PATRICK S. ROBINSON \\ M.R.C.P. \\ B. STEPHEN JENKINS \\ M.R.C.P. \\ MARK V. BRAIMBRIDGE
F.R.C.S.
}

\author{
D. JOHN COLTART \\ M.D., M.R.C.P., F.A.C.C. \\ Michael M. Webb-Peploe \\ F.R.C.P.
}

BRYN T. WILLIAMS
F.R.C.S.

Departments of Cardiology and Cardiothoracic Surgery, St Thomas' Hospital, London, SE1

\begin{abstract}
Summary
The comprehensive experience of coronary artery surgery in a Cardiothoracic Unit over a 31-month period is reviewed. Hospital mortality for elective bypass grafting was $3.9 \%$ overall and $2.5 \%$ in those with good pre-operative left ventricular function. Major influences on hospital mortality were preoperative left ventricular function, extent of coronary artery disease and extent of the surgical procedure undertaken in terms of number of aortocoronary grafts inserted, coronary endarterectomy and particularly concomitant valve surgery or aneurysm resection.

Follow-up experience shows $74 \%$ of grafted patients to be symptom-free and $85 \%$ symptomatically improved one year after surgery with $\mathbf{7 0} \%$ symptomfree and $80 \%$ improved at two years. Early postoperative deaths appear related to early graft closure and recurrence of symptoms postoperatively to late graft closure or progression of coronary disease in the native circulation. The study provides a guide to the relative risks of coronary artery surgery for symptomatic coronary artery disease and expected symptomatic results in the early follow-up period.
\end{abstract}

\section{Introduction}

The construction of aortocoronary bypass grafts, introduced by Favaloro and his colleagues in 1967 (Favaloro, 1968, 1969) as a remedy for obstructive coronary artery disease, is now commonplace. The indications for such surgery range from the most conservative-failed medical management of a severely limited patient - to an aggressively prophylactic approach. The latter aims to conserve

Correspondence: Dr D. John Coltart, M.D., M.R.C.P., F.A.C.C., Department of Cardiology, St Thomas' Hospital, London, SE1.

Requests for offprints: Dr Patrick Robinson, Department of Cardiology, St Thomas' Hospital, London SE1. irreplaceable myocardium (i.e. prevent infarction) and to prolong life. The rationale for surgery as a therapeutic manoeuvre depends, therefore, for the conservative, on a sustained symptomatic improvement, and for the most aggressive, on an increase in life expectancy. A low operative mortality rate and a high long-term graft patency rate thus necessarily become of increasing significance as the indications become less conservative. The extent of coronary arterial disease and the degree of irreversible damage to the myocardium before surgery are important determinants of early mortality and the functional results.

Reports from the larger cardiac centres in America claim a hospital mortality below $6 \%$ for uncomplicated bypass surgery with improvement in $80-90 \%$ of patients surviving operation. These series tend to be selective and do not give an overall picture of the role of coronary artery surgery in the context of a general cardiac surgical programme. The authors now report the comprehensive experience of coronary artery surgery in a cardiothoracic unit over a consecutive 31-month period.

\section{Patients}

Following clinical assessment and diagnostic cardiac catheterization, patients were considered for surgery on the following indications.

\section{Symptomatic}

(1) Stable angina refractory to medical treatment.

(2) Unstable angina refractory to medical treatment.

\section{Anatomical}

(1) Significant left main stem or equivalent coronary artery disease.

(2) Demonstration of significant obstructive coronary artery disease in patients undergoing 
investigation before surgery for: (a) complications of myocardial infarction (mitral regurgitation and left ventricular aneurysm); (b) other valve disease (aortic or mitral valve disease); (c) ventricular dysrhythmias refractory to medical therapy.

Patients were not excluded from surgery on the basis of poor pre-operative left ventricular function if angina was the dominant symptom and the coronary artery anatomy was suitable.

Symptoms were graded according to the New York Heart Association (NYHA) applied to the limiting symptom either angina or dyspnoea. Previous myocardial infarction was established on either a documented hospital admission with a discharge diagnosis of myocardial infarction or on the presence of pathological $Q$ waves on the resting electrocardiogram. Heart size was assessed from a standard postero-anterior chest X-ray. Cardiac catheterization was in most cases an elective procedure with full right and left heart catheterization. Left ventricular ciné-angiograms were taken in the right anterior oblique position. In addition, either a left anterior oblique or left lateral view was obtained. The left ventricular ciné-angiogram was graded visually for:

I normal contraction; II localized dyskinesia of one wall of the ventricle; III localized dyskinesia of two or more walls of the ventricle; IV generalized severe hypokinesia with or without localized regions of dyskinesia.

The end-systolic and end-diastolic volumes and ejection fraction were calculated from the left ventricular ciné-angiogram using a light pen/ computer system (Chatterjee et al., 1971).

Coronary arteriography was performed by the Judkins' technique using multiple views of each coronary artery. Vessel stenosis was considered significant if the lumenal diameter of the main stem or major branches of a coronary artery were reduced by $50 \%$ or more.

The technique of coronary artery surgery is described elsewhere (Favaloro, 1968, 1969). One- hundred and ninety-three patients had aortocoronary bypass grafts. The patients comprised 162 males $C$ aged 31-75 years (mean 50.3 years); and thirty-one females aged 42-75 years (mean 55.1 years). One $\stackrel{0}{?}$ hundred and forty-six patients had aortocoronaryo bypass grafts alone; twenty-six, resection or plication $\underline{\underline{-}}$ of left ventricular aneurysms; nineteen, surgery to $\frac{\bar{\rho}}{\frac{}{\sigma}}$ aortic or mitral valves; and two, resection of $\stackrel{\varnothing}{\propto}$ infarcted myocardium in addition to bypass grafts. Operations performed are shown in Table 1. One patient had a mitral annuloplasty in addition to. aneurysm resection and one had mitral valve $\vec{\omega}$ replacement in addition to resection of infarcted $\stackrel{\omega}{\sigma}$ myocardium. A total of forty-seven patients hado complex surgical procedures.

TABle 1. Operative procedure

\begin{tabular}{lcr}
\hline Procedure & No. of patients \\
\hline $\begin{array}{l}\text { Aortocoronary bypass grafts alone } \\
\quad \text { Coronary endarterectomy }\end{array}$ & 146 & 61 \\
Left ventricular aneurysm surgery & 26 & \\
$\quad$ Aneurysm resection & & 21 \\
$\quad$ Aneurysm plication & 19 \\
Valve surgery & & 8 \\
$\quad$ Aortic valve replacement & & \\
$\quad$ Aortic and mitral valve replacement & & \\
$\quad$ Mitral valve replacement & 2 & \\
Infarct resection & 193 & \\
Total & &
\end{tabular}

In all, 419 vessels were grafted using 416 grafts (sequential grafts to two vessels in the same vascular $\stackrel{\circ}{\mathbb{D}}$

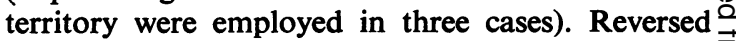
saphenous vein was used for $\mathbf{4 0 4}$ grafts and internal $\overrightarrow{0}$ mammary artery for 12 grafts. Graft numbers and distribution are outlined in Table 2. Coronary endarterectomy was performed in seventy-three patients overall, the distribution of the vessels endarterectomized is shown in Table 3.

Of 146 patients having bypass grafts alone, $144 \frac{5}{3}$ had refractory angina pectoris of which $114(78 \%)$

TABLE 2. Aortocoronary bypass graft numbers and distribution

\begin{tabular}{lcrr}
\hline Aortocoronary bypass grafts & Grafts alone & \multicolumn{2}{c}{ Complex surgery } \\
\hline $\begin{array}{l}\text { Single graft } \\
\text { Left anterior descending coronary artery }\end{array}$ & 30 & 19 & 16 \\
$\quad$ Left circumflex coronary artery & 0 & 10 \\
$\quad$ Right coronary artery & & 11 & 4 \\
Double grafts & 59 & 20 \\
Triple grafts & 49 & 8 \\
Quadruple grafts & 8 & 3 \\
Total & 146 & 47 \\
\hline
\end{tabular}


TABLE 3. Coronary endarterectomy

\begin{tabular}{|c|c|c|}
\hline & Grafts alone & Complex surgery \\
\hline Patients & 61 & 12 \\
\hline Vessels endarterectomized & 77 & 13 \\
\hline Left anterior descending coronary artery & 18 & 4 \\
\hline Left circumflex coronary artery & 4 & - \\
\hline Right coronary artery & 55 & 9 \\
\hline
\end{tabular}

were NYHA class III or IV and thirty NYHA class II. Two patients had no angina, one investigated electively following myocardial infarction and the other with recurrent ventricular arrhythmias. Of the forty-seven patients requiring complex surgical procedures, two suffered recurrent ventricular arrhythmias the remainder were limited by angina or dyspnoea; thirty-eight $(81 \%)$ were NYHA class III or IV and seven NYHA class II. The two patients requiring resection of infarcted myocardium were in severe left ventricular failure one due to an inferior false aneurysm, and the other to severe mitral regurgitation secondary to papillary muscle dysfunction.

Eleven patients were under treatment preoperatively for diabetes mellitus and twelve had been treated for persistent hypertension.

Eighty-three patients $(43 \%)$ had no evidence of previous myocardial infarction, while $103(53.4 \%)$ had evidence of old myocardial infarction (sixty-four, one previous infarct; and thirty-nine, two or more infarcts) and seven (3.6\%) were operated on within 2 months of acute myocardial infarction.

The heart size on chest X-ray was normal in 102 patients. Slight cardiac enlargement was present in fifty-three, moderate in thirty-three and severe in five.

\section{Results}

\section{Hospital mortality: (Table 4)}

Twenty-one of the 193 patients in this series died during the in-hospital period. Ten deaths occurred at operation and eleven in the postoperative period; of the latter, nine died within 14 days of operation and two after a protracted postoperative course. In all the ten patients dying at operation, cardiopulmonary bypass could not be withdrawn owing to either intractable arrhythmias or inability of the left ventricle to sustain an adequate cardiac output without support. Of this group seven of ten had complex surgery of whom three had resection of left ventricular aneurysms, two aortic valve replacement, one aortic and mitral valve replacement and one resection of infarcted myocardium and mitral valve replacement undertaken for cardiogenic shock and severe mitral regurgitation $24 \mathrm{hr}$ after the onset of acute myocardial infarction. A further patient with a $90 \%$ stenosis of the left main coronary artery was operated on as an emergency following probable infarction at the time of cardiac catheterization. At post-mortem there was clear evidence of recent infarction in only two cases who had sustained infarction before surgery and all twenty grafts were patent.

The eleven deaths occurring in the postoperative period include six patients where death was due to poor left ventricular pump function with a persistently low cardiac output and its complications, one due to pulmonary embolism and four due to intractable ventricular fibrillation. Of this group, six of eleven had complex surgery comprising five who had resection of left ventricular aneurysms and one mitral valve replacement. At post-mortem there was evidence of recent infarction in six cases and, of twenty-nine grafts inserted, eighteen $(62 \%)$ were patent.

For uncomplicated elective bypass grafting hospital mortality was $3.9 \%$ overall and $2.5 \%$ for those with good pre-operative left ventricular function (ejection fraction greater than 0.55 ) Table 4. When more complex surgery was undertaken mortality was substantially higher $-21 \cdot 1 \%$ for combined valve surgery and bypass grafting and $30.8 \%$ for combined aneurysm surgery and bypass grafting. Over a similar period twelve patients had aneurysm surgery without bypass grafting with a hospital mortality in this group of $16.7 \%$.

The influence of clinical features, pre-operative left ventricular function and extent of coronary artery disease on hospital mortality in patients having bypass grafts alone is considered in Tables 5 , 6 and 7. The influence of various clinical features is considered in Table 5. Except in the oldest age group (60-69 years), age appears to have little influence while mortality was increased in female patients and when there was a pre-operative history of hypertension or diabetes mellitus.

Pre-operative left ventricular function is considered in Table 6. The figures demonstrate increased early mortality with deterioration of left ventricular function whether reflected in heart size on the preoperative chest X-ray, evidence of old or recent myocardial infarction, the appearance of the left 
TABLE 4. Influence of operative procedure on hospital mortality

\begin{tabular}{lccc}
\hline Procedure & \multicolumn{3}{c}{ Mortality $(\%)$} \\
\hline $\begin{array}{l}\text { Aortocoronary bypass grafts alone } \\
\text { Elective surgery (good left ventricular }\end{array}$ & $8 / 146$ & $5 \cdot 5 \%$ & \\
function, ejection fraction $\geqslant 0 \cdot 55)$ & & $2 / 81$ & $2 \cdot 5 \%$ \\
Elective surgery (all patients) & & $5 / 127$ & $3 \cdot 9 \%$ \\
Emergency surgery & & $3 / 19$ & $15 \cdot 8 \%$ \\
Complex surgery & $13 / 47$ & $27 \cdot 7 \%$ & \\
$\quad$ Left ventricular aneurysm surgery & & $8 / 26$ & $30 \cdot 8 \%$ \\
Valve surgery & & $4 / 19$ & $21 \cdot 1 \%$ \\
Infarct resection & & $2 / 12$ & $50 \%$ \\
Aneurysm surgery without grafts & & $16 \cdot 7 \%$ \\
\hline
\end{tabular}

TABLE 5. Influence of clinical variables on hospital mortality for aortocoronary bypass grafting

\begin{tabular}{lccc}
\hline Clinical features & & Mortality & $\%$ \\
\hline Age (years) & $30-39$ & $1 / 16$ & $6 \cdot 3 \%$ \\
& $40-49$ & $2 / 46$ & $4 \cdot 4 \%$ \\
& $50-59$ & $1 / 68$ & $1 \cdot 5 \%$ \\
Sex & $60-69$ & $4 / 16$ & $25 \%$ \\
& Male & $6 / 121$ & $5 \%$ \\
Hypertension & Female & $2 / 25$ & $8 \%$ \\
Diabetes mellitus & & $1 / 9$ & $11 \cdot 1 \%$ \\
\hline
\end{tabular}

TABLE 6. Influence of pre-operative left ventricular function on hospital mortality for aortocoronary bypass grafting

\begin{tabular}{|c|c|c|}
\hline & Mortality & $\%$ \\
\hline $\begin{array}{l}\text { Heart size on chest X-ray } \\
\text { Normal/slight enlargement } \\
\text { Moderate/severe enlargement }\end{array}$ & $\begin{array}{l}5 / 127 \\
1 / 20\end{array}$ & $\begin{array}{l}3.9 \% \\
5.0 \%\end{array}$ \\
\hline $\begin{array}{l}\text { Previous myocardial infarction } \\
\text { None } \\
\text { Old } \\
\text { Recent (within } 2 \text { months) }\end{array}$ & $\begin{array}{l}2 / 72 \\
4 / 69 \\
2 / 5\end{array}$ & $\begin{array}{r}2 \cdot 8 \% \\
5 \cdot 8 \% \\
40 \cdot 0 \%\end{array}$ \\
\hline $\begin{array}{l}\text { Left ventricular ciné-angiography } \\
\text { I Normal } \\
\text { II One wall dyskinetic } \\
\text { III Two or more walls dyskinetic } \\
\text { IV Generalised severe hypokinesia }\end{array}$ & $\begin{array}{l}4 / 75 \\
2 / 35 \\
2 / 24 \\
0 / 12\end{array}$ & $\begin{array}{l}5 \cdot 3 \% \\
5 \cdot 7 \% \\
8 \cdot 5 \% \\
0\end{array}$ \\
\hline $\begin{array}{l}\text { Left ventricular ejection fraction } \\
\quad \begin{array}{l}\geqslant \\
\quad 0.55 \\
0.25 \text { to } 0.54 \\
<0.25\end{array}\end{array}$ & $\begin{array}{l}3 / 83 \\
4 / 47 \\
0 / 5\end{array}$ & $\begin{array}{l}3 \cdot 6 \% \\
8 \cdot 5 \% \\
0\end{array}$ \\
\hline $\begin{array}{l}\text { Left ventricular end-diastolic pressure } \\
\quad \leqslant 12 \mathrm{mmHg} \\
\quad<12 \mathrm{mmHg}\end{array}$ & $\begin{array}{l}5 / 126 \\
2 / 14\end{array}$ & $\begin{array}{r}4 \cdot 0 \% \\
14 \cdot 3 \%\end{array}$ \\
\hline
\end{tabular}

ventricular ciné-angiogram, left ventricular ejection fraction or left ventricular end-diastolic pressure.

The extent of coronary artery disease and the complexity of the surgery required to provide relief is outlined in Table 7. Early mortality increases progressively with the number of vessels diseased and is substantially higher in the presence of left main coronary artery disease compared with two and three vessel coronary artery disease without left main coronary artery involvement.
Mortality also rises progressively with the numbero of bypass grafts inserted and endarterectomy has an $\underline{3}$. unfavourable influence presumably reflecting more severe coronary disease.

Emergency surgery carries a higher mortality than elective surgery. In this series emergency surgery was undertaken in twenty-three patients $c$ (nineteen had bypass grafting alone). Thirteen of $\frac{}{5}$ the patients had crescendo angina defined as angina of increasing frequency and severity culminating in prolonged rest pain, refractory to medical therapy, $\mathrm{O}$ with no enzymatic or electrocardiographic evidence $\Phi$ of myocardial infarction, and in the presence $\mathrm{Bf} \vec{\bullet}$ significant coronary artery disease. None of the sub-group died. Seven patients were operated की. within 2 months of myocardial infarction (fo 1 r within $24 \mathrm{hr}$ of the onset of infarction) for complications of acute myocardial infarction either persistent pain or left ventricular failure - three of $\mathscr{\varrho}$ these patients died. Three other patients had $\stackrel{\varnothing}{\varnothing}$ emergency surgery one with left ventricular failure $\overrightarrow{\vec{B}}$ and a left ventricular aneurysm and two following 3 cardiac arrests during investigation. Early mortality $\bar{\partial}$ in the group having emergency surgery was $17 \cdot 4 \%$ 응 overall (Table 8 ) and $15.8 \%$ in those having bypass grafts alone (Table 4).

Symptomatic results, recurrent angina and late mortality

Follow-up details for patients having bypass 0 grafting alone are summarized in Table 9. For geographical reasons a number of patients were $\frac{7}{0}$ unavailable for follow-up but these did not differ significantly in their pre-operative evaluation from on those available for regular follow-up. Mean follow- N up was approximately 12 months after surgery. 옹 Over the follow-up period there is a progressive $\omega$ decline of those symptom-free and symptomatically improved with an increasing incidence of recurrent $\stackrel{\circ}{\subset}$ angina. Of the patients, $74 \%$ were symptom-free, $\mathbb{D}$ and $84.9 \%$ improved at 1 year; $70.0 \%$ were symptom-free and $80.0 \%$ improved at 2 years. The incidence of recurrent angina or deterioration $\overrightarrow{\mathbb{D}}$ 
TABLE 7. Influence of extent of coronary artery disease and number of grafts on hospital mortality for aortocoronary grafting

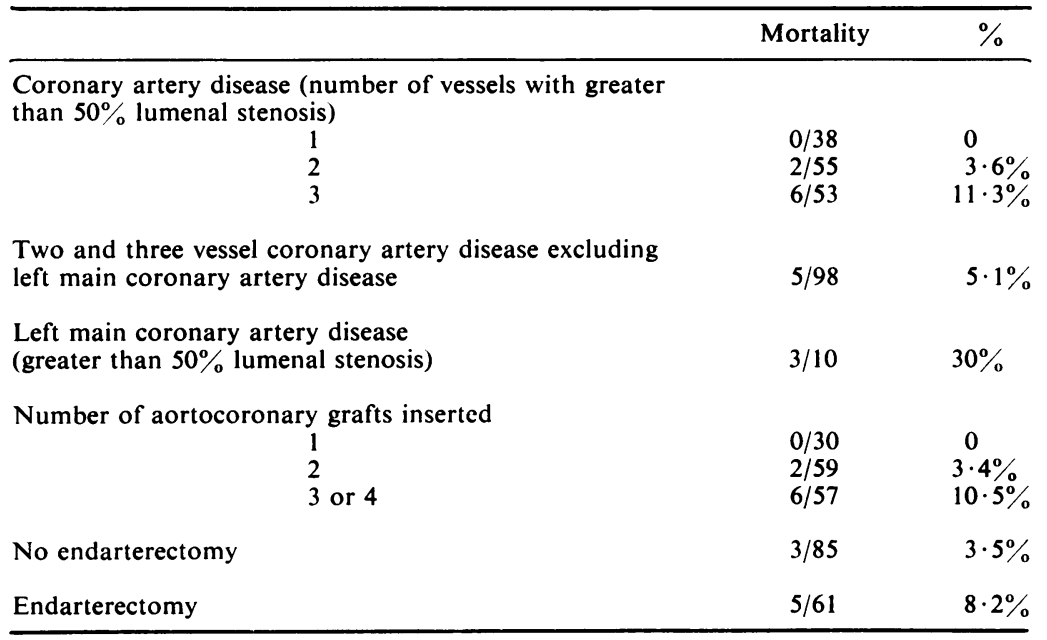

TABLE 8. Hospital mortality for emergency aortocoronary bypass grafting

\begin{tabular}{lcc}
\hline Indication for surgery & Mortality & $\%$ \\
\hline Crescendo angina & $0 / 13$ & 0 \\
Left ventricular failure/aneurysm & $0 / 1$ & 0 \\
Persistent pain or left ventricular failure & & \\
after recent infarction (within 2 months) & $3 / 7$ & $42 \cdot 9 \%$ \\
Cardiac arrest during assessment & $1 / 2$ & $50 \%$ \\
Overall & $4 / 23$ & $17 \cdot 4 \%$ \\
\hline
\end{tabular}

following a period substantially improved was $11.0 \%$ at 1 year and $20.0 \%$ at 2 years, although in a number of cases the recurrent symptoms were mild compared with pre-operatively. Within this group of patients there have been only two late deaths to date; one 2 months and the other 4 months postoperatively - both sudden, and presumed cardiac, deaths. A single patient has had a further documented myocardial infarction during the follow-up period with subsequently severe angina requiring reinvestigation. Overall survival at 1 year after surgery was $93 \cdot 8 \%$.

\section{Reinvestigation}

Reinvestigation has been undertaken in nine patients having aortocoronary bypass grafts with recurrent angina following a period symptom-free or much improved after surgery. In this group preoperatively twenty-seven major arterial segments demonstrated significant coronary artery disease and were considered suitable for bypass grafting. At reinvestigation postoperatively eight of the twenty-seven grafts $(30 \%)$ were patent. Significant coronary artery disease was demonstrated in three arteries previously free of disease. There was evidence of progression of disease in the native circulation proximal to the grafts in eleven vessels eight of which were completely occluded.

TABLE 9. Follow-up details of patients undergoing aortocoronary bypass grafting. Mean length of follow-up $12 \cdot 7$ months. Total number of patients 146 , hospital deaths eight, geographical loss to followup 26

\begin{tabular}{|c|c|c|c|c|}
\hline & 3 months & 6 months & 12 months & 24 months \\
\hline Number of patients ( $\%$ follow-up) & $\begin{array}{r}112(99 \cdot 1 \%) \\
91(82 \cdot 0 \%)\end{array}$ & $\begin{array}{l}100(99 \%) \\
78(78 \cdot 8 \%)\end{array}$ & $\begin{array}{l}74(98 \cdot 6 \%) \\
54(74 \cdot 0 \%)\end{array}$ & $\begin{array}{l}30(100 \%) \\
21(70.0 \%)\end{array}$ \\
\hline Improved & 12 & 10 & 7 & 1 \\
\hline Unaltered & 2 & 3 & 3 & 1 \\
\hline *Symptomatically improved $(\%)$ & $103(92 \cdot 8 \%)$ & $88(88 \cdot 9 \%)$ & $62(84 \cdot 9 \%)$ & $24(80 \cdot 0 \%)$ \\
\hline Recurrent angina $(\%)$ & $5(4 \cdot 5 \%)$ & $6(6 \cdot 1 \%)$ & $8(11 \cdot 0 \%)$ & $6(20 \cdot 0 \%)$ \\
\hline Late infarction $(\%)$ & $1(0.9 \%)$ & - & - & - \\
\hline †Late death $(\%)$ & $1(0.9 \%)$ & $2(2 \cdot 0 \%)$ & $1(1 \cdot 4 \%)$ & $1(3 \cdot 3 \%)$ \\
\hline
\end{tabular}

* Includes those symptom-free, symptomatically improved and those with minimal recurrent symptoms compared with pre-operatively.

+ Cumulative. 


\section{Discussion}

Aortocoronary bypass grafting was introduced by Favaloro and his associates at the Cleveland Clinic in 1967 (Favaloro, 1968, 1969). Since that time it has become a widely practised treatment for symptomatic coronary artery disease. The merit or otherwise of surgery for asymptomatic coronary artery disease remains to be established. In this series the indication for surgery was, in general, severe symptomatic coronary artery disease refractory to medical therapy. Most patients, particularly those with stable angina pectoris, had an adequate trial of medical treatment with nitrates and $\beta$-blocking drugs before consideration of coronary arteriography and coronary artery surgery. Other indications for surgery included patients severely symptomatic with complications of obstructive coronary artery disease and those with valvular disease and significant coronary artery disease. Patients with left main coronary artery disease tended to present earlier and with severe symptoms, however, once this lesion was established arteriographically, surgery was considered the treatment of choice.

The results presented are a comprehensive review of coronary artery surgery in the cardiothoracic unit of a teaching hospital over a 31-month period. The aim of the review was to establish whether such a cardiothoracic unit could achieve comparable results to the previously published reports from larger cardiac centres abroad specializing in coronary artery surgery and to analyse those factors which influence early mortality.

For elective bypass grafting hospital mortality was $3.9 \%$ and in eighty-one patients with good pre-operative left ventricular function (ejection fraction greater than 0.55 ) mortality was $2.5 \%$. Previous reports state hospital mortality for uncomplicated bypass grafting in the range $1 \cdot 3-12 \%$ (Favaloro, 1972; Manley and Johnson, 1972; Reul et al., 1972; Collins et al., 1973; Hall et al., 1973; Sheldon et al., 1973; Cooley et al., 1973; Forker et al., 1974; Cannom et al., 1974; Anderson et al., 1974; Najmi et al., 1974; Balcon et al., 1974; Bennett et al., 1974; Kouchoukos, Kirklin and Oberman, 1974). In the larger series comprising more than 500 cases (Favaloro, 1972; Manley and Johnson, 1972; Reul et al., 1972; Hall et al., 1973; Sheldon et al., 1973; Cooley et al., 1973; Cannom et al., 1974; Bennett et al., 1974; Kouchoukos et al., 1974) hospital mortality ranges from 1.3 to $7 \cdot 1 \%$ with the Cleveland Clinic experience of 4935 bypass graft operations from 1967 to 1973 demonstrating an overall hospital mortality of $1.3 \%$ and a progressive decline in hospital mortality over the years with increasing experience and more exacting selection of patients for surgery, particularly the exclusion of those with severely impaired left ventricular function (Bennett et al., 1974). Two other factors are perhaps of importance. Firstly the proportion of multiple $\stackrel{.}{\Rightarrow}$ grafts suggesting more diffuse coronary artery $\stackrel{?}{+}$ disease was $116 / 146(79 \%)$ in the present series while $\bar{c}$ this proportion is often lower in other series; 흘 $2967 / 4694(63 \%)$ of patients having bypass grafts $\frac{\bar{s}}{\circ}$ alone in the Cleveland Clinic series from 1970 to 1973 ه (Bennett et al., 1974). Secondly, although difficult to establish, the patient who is referred to a surgical os group in their early experience is not infrequently $\vec{\circ}$ the patient with severe functional disability and $\vec{\exists}$ 'end-stage' disease. Smaller series more directly comparable with the present one demonstrate a $\overline{8}$ hospital mortality for uncomplicated bypass grafting 3 . of $6.2 \%$ (Forker et al., 1974), 6.4\% (Balcon et al., ir 1974 ) and $12 \%$ (Najmi et al., 1974).

The possible influences on hospital mortality in $\mathcal{L}^{2}$ uncomplicated bypass grafting are considered os separately to demonstrate trends although clearly in $\overrightarrow{0}$ many instances these risk factors are not independent 은 and act either through increasing extent and severity of coronary artery disease or through deterioration of pre-operative left ventricular function.

Except in the oldest age group (60-69 years) age had no clear influence on hospital mortality. however, mortality was increased in female patients $\overrightarrow{0}$ in those suffering from sustained hypertensio pre-operatively and particularly in those wit? diabetes mellitus.

A major influence on hospital mortality was the pre-operative state of the left ventricular myocardium. Mortality was increased from $3.9 \%$ in those with normal heart size or slight enlargement on chest X-ray to $5.0 \%$ in those with moderate or severe cardiac enlargement. Elevation of left ventricular end-diastolic pressure $(>12 \mathrm{mmHg}$ at rest) resulted in a hospital mortality of $14.3 \%$ compared to $4 \%$ for those with normal left ventricular end-diastolic pressure. In reported series, evidence of congestive cardiac failure resulted in increased hospital mortality from $1.9 \%$ to $29 \%$ (Kouchoukos et al., 1974) and from 3.9 to $19 \%$ (Kaiser et al., 1972) and elevation of left ventricular end-diastolic pressure ( $>18 \mathrm{mmHg}$ at rest) from 9 to $30 \%$ (Kay et al., 1972).

The present results show a progressive increase in hospital mortality with increasing left ventricular dyskinesia whether reflected in the appearance of the left ventricle on ciné-angiograms or in the left ventricular ejection fraction. These trends are noted in other series. Hospital mortality ranged from $5 \%$ (normal left ventricle) to $37 \%$ (two walls dyskinetic) (Manley and Johnson, 1972) and from 4\% (normal) to $27 \%$ (two walls dyskinetic) (Forker et al., 1974). A similar trend is seen with respect to left ventricular ejection fraction; when greater than 0.45 , hospital 
mortality was $3 \%$ compared to $31 \%$ when less than 0.2 (Kay et al., 1972). In another series when ejection fraction was greater than $0 \cdot 25$, hospital mortality was $4 \%$ and $25 \%$ when ejection fraction was less than 0.25 (Oldham et al., 1972).

Prior myocardial infarction and the interval between infarction and surgery is a second major influence on hospital mortality. In a study from the Texas Heart Institute (Dawson et al., 1974) reviewing 1700 operations, early mortality in those with no previous infarct was $4.1 \%$, old infarction $6.9 \%$ and recent infarction $14.5 \%$ (surgery $0-24 \mathrm{hr}$ after infarction $36.4 \%, 2-7$ days after infarction $40 \%$, 7-30 days after infarction $16.4 \%$ and $31-60$ days after infarction $5.8 \%$ ). In the present series the trend was similar. In those with no previous infarct mortality was $2.8 \%$, old infarction $5.8 \%$ and surgery within 2 months of infarction (three out of five within $24 \mathrm{hr}$ of infarction) $40 \%$. Other series have reported high mortality for surgery for the complications of acute myocardial infarction $54.2 \%$ (Buckley et al., $1971)$ and for surgery following infarction during cardiac catheterization $36 \%$ (Reul et al., 1973).

The extent of coronary artery disease showed a clear influence on hospital mortality, this increased from no deaths with single vessel disease to $11.3 \%$ with triple vessel disease, and from $5.1 \%$ with double or triple vessel disease with a normal left main coronary artery to $30 \%$ when there was significant disease of the left main coronary artery. These trends are described in some previous reports; no mortality for single vessel disease and $26.1 \%$ mortality for triple vessel disease (Reul et al., 1972); $2.5 \%$ mortality for single vessel disease and $14.1 \%$ mortality for quadruple vessel disease (Najmi et al., 1974). However, this trend is not demonstrated in other reports (Hall et al., 1973; Kouchoukos et al., 1974). Mortality for surgery in the presence of left main coronary artery disease is consistently high in reported series $8.2 \%$ (Pichard et al., 1973), 10.7\% (Zeft et al., 1974), 14\% (Takaro et al., 1976), 28.4\% (Sharma et al., 1973), and 39\% (Kisslo et al., 1973).

Emergency surgery carried a higher mortality than elective surgery with a hospital mortality for emergency bypass grafting of $15.8 \%$. This mortality reflects the high risk of surgery in the situation of recent myocardial infarction while, interestingly, there were no deaths in thirteen patients operated on for crescendo angina which had failed to respond to aggressive medical therapy.

The surgical procedure carried out strongly influenced hospital mortality. Mortality increased with the number of bypass grafts inserted from no deaths with single grafts to $10.5 \%$ mortality with three or four grafts and concomitant endarterectomy resulted in increased mortality from 3.5 to $8.2 \%$. Resection of left ventricular scars or valve surgery led to an increase in mortality. In this series the mortality for combined bypass grafting and aneurysm resection was $30.8 \%$ (compared with $16.7 \%$ for aneurysm resection alone over the same period) and for combined valve surgery and bypass grafting $21.1 \%$ - this latter group including patients with primary valve disease and those with mitral dysfunction secondary to poor left ventricular function or papillary muscle damage. The Texas Heart Institute series (Cooley et al., 1973) reviewed 1492 operations, 1289 patients had bypass grafts alone with a mortality of $7 \cdot 1 \%$, eighty-six patients had combined aneurysm surgery and a mortality of $16.3 \%$ and eighty-four patients had combined valve surgery and a mortality of $23.8 \%$. The Baylor series (Reul et al., 1972), reviewing 1287 operations, yielded early mortality figures of $5 \cdot 2,18.2$ and $28 \cdot 1 \%$ respectively. Deaths at the time of operation occurred with patent grafts, suggesting that the severely compromised myocardium has exacting metabolic requirements and that hypoxia or other metabolic disturbances may rapidly produce an irreversible situation. Patients dying postoperatively commonly had occluded grafts and evidence at post-mortem of recent infarction with the consequences of reduced pump function and predisposition to arrhythmias. Early graft occlusion may be causally related to peri-operative infarction and early death.

Symptomatic results are excellent, $74 \%$ of patients having bypass grafts alone were symptom-free at one year after surgery, $85 \%$ symptomatically improved. At 2 years after surgery $70 \%$ were symptom-free and $80 \%$ improved. In reported series with mean length of follow-up between 6 months and 5 years after surgery those symptom-free ranged from 33 to $79 \%$ and improved from 60 to $96 \%$ with a tendency to deterioration of results with length of follow-up (Manley and Johnson, 1972; Reul et al., 1972; Collins et al., 1973; Hall et al., 1973; Sheldon et al., 1973; Cannom et al., 1974; Anderson et al., 1974; Kouchoukos et al., 1974; Najmi et al., 1974; Balcon et al., 1974; Bennett et al., 1974). Reported graft patency at 6-12 months after surgery is in the range $73-87 \%$ (Favaloro, 1972; Manley and Johnson, 1972; Reul et al., 1972; Kaiser et al., 1972; Hall et al., 1973; Sheldon et al., 1973; Anderson et al., 1974; Kouchoukos et al., 1974), and symptomatic results generally correlate well with this. In the present study, reinvestigation was not undertaken routinely but the excellent symptomatic results suggest adequate graft patency rates. A proportion of patients demonstrate recurrent angina or deterioration following a period symptom-free or substantially improved, this proportion increasing with interval following surgery. In this series, $11.0 \%$ of patients had recurrent 
angina at 1 year after surgery and $20.0 \%$ at 2 years. A high proportion of these patients with recurrent angina have been reinvestigated and both progression of disease in the native coronary circulation and occlusion of grafts was common - the latter presumably representing late graft occlusion. There have been only two late deaths in this series during the follow-up period and a single documented late myocardial infarction.

The number of operations performed and the limited period of follow-up do not allow generalizations as to the effects of surgery on longevity. In a large series of patients with angiographically documented coronary artery disease, studied before coronary artery surgery was widely available, the 1-year mortality (according to the number of vessels diseased) was single vessel disease $4 \%$, double vessel disease $12 \%$, triple vessel disease $22 \%$ and left main coronary artery disease $30 \%$ (Bruschke, Proudfit and Sones, 1973a). The mortality was considerably higher in those with poor left ventricular function (Bruschke et al., 1973b) and overall 1 -year survival was $88.5 \%$.

Both medical and surgical therapy have advanced since this early series was concluded and a recently reported study - the Veterans Administration Cooperative Study of surgery for coronary artery occlusive disease - with random allocation of patients to medical and surgical therapy reveals an early surgical mortality of $5.6 \%$ and 1 -year survival rates for surgery of $93 \%$ and for medical therapy of 95\% (Murphy et al., 1977; Detre, Hultgren and Takaro, 1977). This excludes a subgroup with left main coronary artery disease in whom early surgical mortality was $14 \%$ and 1 -year survival rates for surgery and medical therapy were 85 and $71 \%$ respectively (Takaro et al., 1976). In the present series of patients, most of whom were severely symptomatic and had not responded to adequate medical therapy, overall hospital mortality for elective grafting was $3.9 \%$ and 1-year survival $93.8 \%$.

The overall results from a British teaching hospital with a relatively small experience thus compare favourably with results from the much larger series from the United States. The increased mortality from operation in the presence of impaired left ventricular function, diabetes, hypertension and recent infarction should be noted and quantitated when selecting patients disabled by angina for a successful pain-relieving procedure.

\section{References}

Anderson, R.P., Rahimtoola, S.H., BoncheK, L.I. \& StarR, A. (1974) The prognosis in patients with coronary artery disease after coronary bypass operations. Time related progress of 532 patients with disabling angin pectoris. Circulation, 50, 274.

Balcon, R., Honey, M., Rickards, A.F., Sturridge, M.F., WALSH, W., Wilkinson, R.K. \& WRIGHT, J.E.C. (1974 Evaluation by exercise testing and atrial pacing of the results of aorto-coronary bypass surgery. British Heato Journal, 36, 841.

BenNeTt, D.J., Loop, F.D., Sheldon, W.C. \& EFfler, D. (1974) Direct myocardial revascularization. Operative mortality in the Cleveland Clinic experience. Clevelang Clinic Quarterly, 41, 51.

Bruschke, A.V.G., Proudfit, W.L. \& Sones, F.M. (1973œ9 Progress study of 590 consecutive non-surgical cases of coronary artery disease followed 5-9 years. I. Arteriographic correlations. Circulation, 47, 1147.

Bruschke, A.V.G., Proudfit, W.L. \& Sones, F.M. (1973b Progress study of 590 consecutive non-surgical cases coronary artery disease followed 5-9 years. II. Ventricules graphic and other correlations. Circulation, 47, 1154.

BuCKLeY, M.J., Mundth, E.D., DAGgetT, W.M., Dig Sanctis, R.W., Sanders, C.A. \& Austen, W.G. (1971. Surgical therapy for early complications of myocardia infarction. Surgery, 70, 814.

Cannom, D.S., Miller, D.C., Shumway, N.E., Fogartio T.J., Daily, P.O., Hu, M., Brown, B. \& Harrison, D.Co (1974) The long term follow-up of patients undergoing saphenous vein bypass surgery. Circulation, 49, 77.

Chatterjee, K., Sacoor, M., Sutton, G.C. \& Miller. G.A.H. (1971) Assessment of left ventricular function b\& single-plane cineangiographic volume analysis. Britis Heart Journal, 33, 565.

Collins, J.J., Cohn, L.H., Sonnenblick, E.H., Herman M.V., Cohn, P.F. \& Gorlin, R. (1973) Determinantf of survival after coronary artery bypass surgery. Circulatisn 48 (Suppl. 3), 132.

Cooley, D.A., Dawson, J.J., Hallman, G.L., Sandife F.M., WuKasch, D.C., Garcia, E. \& Hall, R.J. (19 39 Aortocoronary saphenous vein bypass. Results in 149 patients with particular reference to patients with comb plicating features. Annals of Thoracic Surgery, 16, 380.

Dawson, J.T., Hall, R.J., Hallman, G.L. \& Cooley, D.A (1974) Mortality in patients undergoing coronary arterf bypass surgery after myocardial infarction. America $\overrightarrow{8}$ Journal of Cardiology, 33, 483.

Detre, K.M., Hultgren, H.N. \& Takaro, T. (1977 Veterans Administration Cooperative Study of Surger for coronary artery occlusive disease. III. Methods and base line characteristics, including experience with medicat treatment. American Journal of Cardiology, 40, 212.

FAVAloro, R.G. (1968) Saphenous vein autograft replace. ment of severe segmental coronary artery occlusion? operative technique. Annals of Thoracic Surgery, 5, 334.

FAVALORO, R.G. (1969) Saphenous vein graft in the surgicad treatment of coronary artery disease. Operative technique Journal of Thoracic and Cardiovascular Surgery, 58, 178.

FAVALORo, R.G. (1972) Direct and Indirect coronary surgery? Circulation, 46, 1197.

Forker, A.D., ReEse, H.E., Weaver, W.F., Wilson, C.S. Buchman, R. \& CARveth, S.W. (1974) Results of elective aortocoronary saphenous vein graft surgery in a comos munity hospital. Circulation, 49, 334.

Hall, R.J., Dawson, J.T., CoOley, D.A., Hallman, G.L WuKasch, D.C. \& Garcia, E. (1973) Coronary arter\& bypass. Circulation, 48 (Suppl. 3), 146.

Kaiser, G.C., Barner, H.B., Willman, V.L., Mudd, J.G., Westura, E.W. \& Alves, L.E. (1972) Aortocoronaf bypass grafting. Archives of Surgery, 105, 319.

Kay, J.H., Redington, J.V., Mendez, A.M., Zubiate, P \& DunNe, E.F. (1972) Coronary artery surgery for the patient with impaired left ventricular function. Circulation 46 (Suppl. 2), 49. 
Kisslo, J., Peter, R., Behar, V., Bartel, A. \& Kong, Y. (1973) Left main coronary artery stenosis. Circulation, 48 (Suppl. 4), 57.

Kouchoukos, N.T., Kirklin, J.W. \& Oberman, A. (1974) An appraisal of coronary bypass grafting. Circulation, 50, 11.

MANLEY, J.C. \& JoHNSON, W.D. (1972) Effects of surgery on angina (pre and post infarction) and myocardial function (failure). Circulation, 46, 1208.

MurPhy, M.L., Hultgren, H.N., Detre, K., Thomsen, J. \& TAKARO, T. and participants of the V.A. Cooperative Study. (1977) Treatment of chronic stable angina. A preliminary report of survival data of the randomised Veterans Administration Cooperative Study. New England Journal of Medicine, 297, 621.

Najmi, M., Ushiyama, K., Blanco, G., Adam, A. \& Segal, B.L. (1974) Results of aortocoronary artery saphenous vein bypass surgery for ischemic heart disease. American Journal of Cardiology, 33, 42.

Oldham, H.N., Kong, Y., Bartel, A.G., Morris, J.J., Behar, V.S., Peter, R.H., Rosati, R.A., Young, W.G. \& SABISTON, D.C. (1972) Risk factors in coronary artery bypass surgery. Archives of Surgery, $105,918$.

Pichard, A.D., Sheldon, W.C., Shinj, K., Effler, D.B. \& SONES, F.M. (1973) Severe arteriosclerotic obstruction of the left main coronary artery: Follow-up results in 176 patients. Circulation, 48 (Suppl. 4), 53.
Reul, G.J., Morris, G.C., Howell, J.F., Crawford, E.S. \& STELTER, W.J. (1972) Current concepts in coronary artery surgery. A critical analysis of 1287 patients. Annals of Thoracic Surgery, 14, 243.

Reul, G.J., Morris, G.C., Howell, J.F., Crawford, E.S. \& STElTER, W.J. (1973) Emergency coronary artery bypass grafting in the treatment of myocardial infarction. Circulation. 48 (Suppl. 3), 177.

Sharma, S., Khaja, J., Heinle, R., Goldstein, S. \& Easley, R. (1973) Left main coronary (LMC) artery lesions: risk of catheterisation, exercise test and surgery. Circulation, 48 (Suppl. 4), 53.

Sheldon, W.C., Rincon, G., Effler, D.B., Proudfit, W.L. \& SONES, F.M. (1973) Vein graft surgery for coronary artery disease. Survival and angiographic results in 1000 patients. Circulation, 48 (Suppl. 3), 184.

Takaro, T., Hultgren, H.N., Lipton, M.J. \& Detre, K.M. (1976) The Veterans Administration Cooperative randomised study of surgery for coronary artery occlusive disease. II. Subgroup with significant left main lesions. Circulation, 54 (Suppl. 3), 107.

Zeft, H.J., Manley, J.C., Huston, J.H., Tector, A.J., AUER, J.E. \& JoHNSON, W.D. (1974) Left main coronary artery stenosis. Results of coronary bypass surgery. Circulation, 49, 68 